\title{
ABUTMENT-PILE-SOIL INTERACTION OF A PSC BRIDGE UNDER SEISMIC LOADING
}

\author{
Ravi kiran $\mathbf{R}^{1}$, Avinash A. $\mathbf{R}^{2}$, Srinivas R.G ${ }^{3}$, Kiran $^{4}$ \\ ${ }^{1}$ Post Graduate student, Structural Engineering, Manipal Institute of Technology Manipal, Karnataka, India \\ ${ }^{2}$ Assistant Professor, Civil Engineering, Manipal Institute of Technology, Karnataka, India \\ ${ }^{3}$ Structural Engineer, kinetix engineering Pvt lmt, Bangalore, Karnataka, India \\ ${ }^{4}$ Structural Engineer, stup consultancy India Pvt lmt, Bangalore, Karnataka, India
}

\begin{abstract}
The practical orientation of all the bridge structures are not straight, they may be skewed to some angles. A skewed bridge is one in which the major axis of the sub structure is not perpendicular to the longitudinal axis of the super structure.. The structural response of a skewed bridge to seismic loads gets significantly altered by the skew angles of the sub structure. Sub structure components consist of abutments, piers and foundations. These components always rest in the soil, hence the response of the structure caused by the flexibility of the foundation soil, as well as the response of the soils caused by the presence of the structure need to be assessed. Hence the study of soil structure interaction of sub structure (Interaction of Soil-Abutment-Pile) shows the behaviour of the sub structure and the soil due to seismic loadings. A Two span continuous prestressed concrete box girder bridge is selected as the super structure of the bridge and Finite element package SAP2000 V 14.2.4 software is used to model the bridge and to perform the analysis. The soil is modelled as five types of springs for which the spring stiffness are determined based on the guidelines given by American Petroleum Institute (API). These springs are modelled in SAP2000 as link elements. Earthquake record of the two major earthquakes Electro and Coalinga are collected from Pacific Earthquake Engineering Research (PEER). The input accelerations are scaled down to the acceleration of the Bangalore region and the time history analysis is performed. The super structure and the sub structure are modelled separately and the soil structure interaction is carried out. The response of the sub structure is obtained in the form of displacement, velocity, acceleration and spectral displacement, spectral velocity and spectral acceleration for the models with and without soil structure interaction.
\end{abstract}

Keywords: skew angle; Soil structure interaction; spectral displacement; spectral velocity $* * *$

\section{INTRODUCTION}

Several experimental and analytical investigations on bridges have been carried out over past 50 years and the important advances have been made in both integral and non integral reinforced concrete bridges.

[1] Shamsabadi (2006) has discussed about abutment soil interaction of skew bridges in many of his papers. Three dimensional models of single-, two and three-span box girder bridges with seat-type abutments, single and two-column bents and various skew angles are presented. Abutment-soil interaction was modeled by nonlinear normal springs skewed to the principal bridge axis.. The analyses shows that the superstructure undergoes significant rotations about the vertical axis that result in permanent lateral deck offset at the abutments.[3]S.Erhan (2010) has studied about the effect of modeling assumptions and simplifications on the seismic analyses results of integral bridges (IBs) are investigated. For this purpose, five structural models of IBs are built in decreasing levels of complexity starting from a nonlinear structural model including the true behaviour of the foundation and backfill soil and gradually simplifying the model to a level where the effect of backfill and foundation soil is totally excluded. Nonlinear time history analyses of the modeled IBs are then conducted using a set of ground motions with various intensities representing small, medium and large intensity earthquakes. The analyses results are then used to assess the effect of modelling complexity level on the seismic behaviour of IBs. The nonlinear soil-bridge interaction is found to have considerable effects on the seismic behaviour of IBs under medium and large intensity earthquakes. George L.England and Neil C.M.Tasang (2005) have discussed about the Design of Soil Loading for Integral Bridges in United Kingdom, the adoption of an Integral type of bridge is recommended for deck lengths shorter than $60 \mathrm{~m}$. The behaviour of integral bridges is dominated by critical (daily and seasonal) length changes in the bridge deck and the resulting effects of cyclical horizontal displacements to the back fill soil of the abutments. [4]N.P. Tongaonkar, R.S. Jangid (2003), have studied about the modern transportation facilities demand that the bridges are to be constructed across the gorges that are located in seismically active areas and at the same time the site conditions compel the engineers to rest 
the pier foundation on soil. The purpose of this study is to assess the effects of soil-structure interaction (SSI) on the peak responses of three-span continuous deck bridge seismically isolated by the elastomeric bearings. The soil surrounding the foundation of pier is modelled by frequency independent coefficients and the complete dynamic analysis is carried out in time domain using complex modal analysis method. In order to quantify the effects of SSI, the peak responses of isolated and non-isolated bridge (i.e. bridge without isolation device) are compared with the corresponding bridge ignoring these effects. A parametric study is also conducted to investigate the effects of soil flexibility and bearing parameters (such as stiffness and damping) on the response of isolated bridge system. It is observed that the soil surrounding the pier has significant effects on the response of the isolated bridges and under certain circumstances the bearing displacements at abutment locations may be underestimated if the SSI effects are not considered in the response analysis of the system.

\section{METHODOLOGY}

\subsection{Introduction}

It is seen that exhaustive work has been carried out on SoilAbutment Interaction of Integral bridges subjected to seismic loads. The behaviour of Sub structure to the seismic forces depends upon the type of the super structure. Normally the abutments are also provided in the skewed direction if the bridge super structure is skewed. Hence the behaviour of abutments of skewed bridges is different when compared with that of abutments of normal bridges.

\subsection{Aim of the Study}

The aim of the present investigation is to compare the soilabutment-pile interaction of skewed and normal bridges subjected to seismic loading. The Prestressed concrete Box girder bridge is considered as the super structure and the sub structure consists of abutments and piles.

\subsection{Scope of Study}

Present study deals with the soil-abutment, and soil-pile interaction of a comparative study of normal and skewed PSC Non integral bridge. The bridge considered in this study is a concrete box girder bridge having a total span of bridge is $100 \mathrm{~m}$ (2-span of $50 \mathrm{~m}$ each) and height of each abutment is $5 \mathrm{~m}$ and of pier is $7 \mathrm{~m}$ and loading on bridge is as per IRC norms. Effect of soil structure interaction in the bridge is analyzed by:

A) Superstructure modeled using SAP2000

B) Substructure modeled separately by SAP2000.

Using SAP2000 bridge model for 3-Dimensional modelled, seismic analysis for each model is analyzed using time history analysis and response spectrum analysis, for a site specific analysis is performed considering the local site effects. Soil springs are modeled according to API guidelines. The time history data of El Centro and Coalinga earthquake are considered and the response of both normal and skew bridges are compared. The soil interacting with the foundation of the structure is modelled by five types of Winkler springs such as 1) Abutment passive springs,

2) End bearing (q-z springs),

3) Lateral (p-y springs),

4) Axial (t-z springs), and

5) Shallow foundation bearing (Q-u springs) springs

The modelling of Lateral (p-y) springs, Axial ( $\mathrm{t}-\mathrm{z}$ ) springs and End bearing ( $\mathrm{q}-\mathrm{z})$ springs are calculated based on American Petroleum Institute (API) guidelines for service condition (nonseismic).

\section{MODELLING AND ANALYSIS OF BRIDGE SUPERSTRUCTURE \& SUB-STRUCTURE}

\subsection{Introduction}

A typical prestressed concrete box girder bridge shown in fig 1 is considered for the soil structure interaction problem. The box girder bridge considered for analysis is $100 \mathrm{~m}$ long bridge with 2 spans of equal lengths of $50 \mathrm{~m}$ each. The abutment is $5 \mathrm{~m}$ tall and it is supported on pile cap of $1 \mathrm{~m}$ thick which rests on 6 concrete piles of $7 \mathrm{~m}$ height having a diameter of $0.75 \mathrm{~m}$ and piers are $10 \mathrm{~m}$ tall, the backfill considered is sand. The abutment is supported on pile foundation with single row of concrete piles. The location of the bridge is in Bangalore. It is an important bridge as per IRC classification which has a carriage way of $10 \mathrm{~m}$ with median $0.5 \mathrm{~m}$ wide and kerbs of 0.3 , it is designed to accommodate two lane traffic. The bridge is located in dry site where no Ground water table is available and the Backfill soil is sand and hence the water retention is remote due to drainage provisions. The bridge is a concrete bridge with M-60 grade concrete for superstructure and M-35 grade for substructure and $\mathrm{Fe}-415$ grade steel for reinforcement. The material properties are as given below.

\subsection{Material Properties}

1) M-60 Grade concrete
$\mathrm{E}=4.415 \times 10^{7} \mathrm{kN} / \mathrm{m}^{2}$
$\mu=0.15$
$\alpha=9.9 \times 10^{-6}$
Unit weight, $\mathrm{g}=25 \mathrm{kN} / \mathrm{m}^{3}$
fck $=60 \mathrm{MPa}$

2) M-35 Grade concrete

$\mathrm{E}=2.958 \times 10^{7} \mathrm{kN} / \mathrm{m}^{2}$

$\mu=0.15$

$\alpha=9.9 \times 10^{-6}$

Unit weight, $g=25 \mathrm{kN} / \mathrm{m}^{3}$

$\mathrm{fck}=35 \mathrm{MPa}$ 


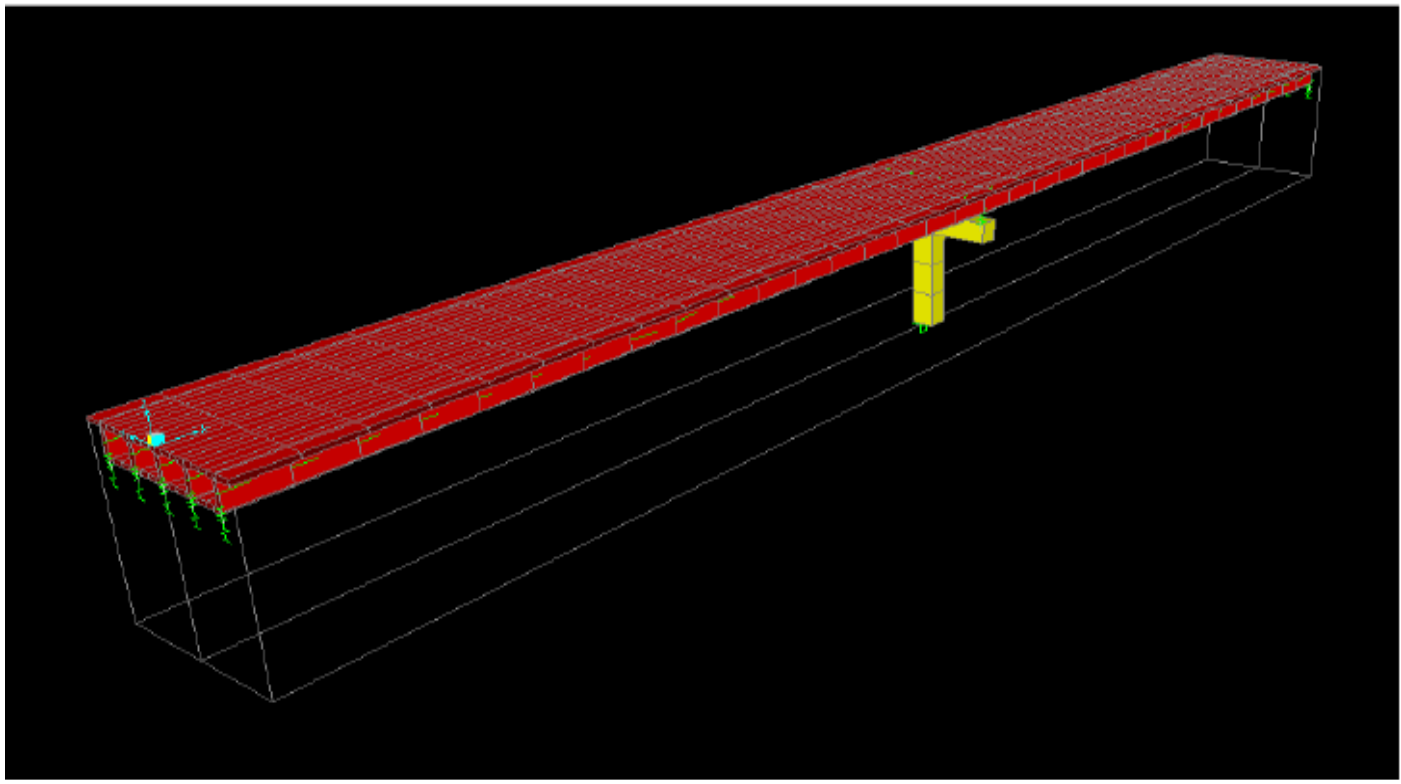

Fig. 1 Model of PSC Box girder Bridge in SAP2000

Table 1 showing Soil Profile properties

\begin{tabular}{|c|c|c|c|c|c|c|c|c|c|c|c|}
\hline \multirow[t]{2}{*}{$\begin{array}{l}\text { Sl } \\
\text { No }\end{array}$} & Soil Strata & $\begin{array}{l}\text { Depth of } \\
\text { soil layer }\end{array}$ & $\mathrm{N}-\mathrm{Val}$ & $\gamma$ & $\begin{array}{c}\text { Over } \\
\text { burden } \\
\text { pressure }\end{array}$ & $\mathrm{N}_{\mathrm{c}}$ & $\mathrm{N}$ & N60 & $\phi$ & Vs & G \\
\hline & & & & $\left(\mathrm{kN} / \mathrm{m}^{3}\right)$ & $\left(\mathrm{kN} / \mathrm{m}^{2}\right)$ & & & & (deg) & $(\mathrm{m} / \mathrm{s})$ & $\left(\mathrm{kN} / \mathrm{m}^{2}\right)$ \\
\hline 1 & \multirow{3}{*}{$\begin{array}{l}\text { Reddish } \\
\text { Brown/ Pink } \\
\text { Sandy silt }\end{array}$} & $0.0-1.50$ & 16 & 16 & - & - & - & - & 32 & - & - \\
\hline 2 & & $1.50-3.0$ & 20 & 16 & 24 & 1.4 & 28 & 24.0352 & 32 & 322.78 & 169929.46 \\
\hline 3 & & $3.0-4.50$ & 25 & 16 & 48 & 1.2 & 30 & 25.752 & 35 & 334.11 & 182067.28 \\
\hline 4 & \multirow{4}{*}{$\begin{array}{l}\text { Reddish white } \\
\text { medium to } \\
\text { dense Sandy } \\
\text { silt }\end{array}$} & $4.50-6.0$ & 34 & 17 & 73.5 & 1.1 & 37.4 & 32.104 & 36 & 373.049 & 241163.28 \\
\hline 5 & & $6.0-7.50$ & 45 & 17 & 99 & 1 & 45 & 38.628 & 38 & 409.20 & 290169.72 \\
\hline 6 & & $7.50-9.0$ & 50 & 18 & 126 & 0.9 & 45 & 38.628 & 38 & 409.20 & 307238.53 \\
\hline 7 & & $9.0-10.50$ & 50 & 18 & 153 & 0.85 & 42.5 & 36.482 & 40 & 397.67 & 290169.72 \\
\hline
\end{tabular}

246789.67

\subsection{Analysis of Bridge Super Structure and}

\section{Substructure in SAP2000}

Three dimensional model of the bridge super structure is modeled in SAP2000 and loadings are applied according to IRC specifications for Normal and Skew edges. The substructure is modeled separately and the reactions from the super structure are applied as point loads at the support of bearings on the top of the abutments for both Normal and Skewed abutments. The load and load combinations considered are as follows:

Loads considered for analysis:
1) Dead load (DL)
2) Prestress
3) Bridge live(as per IRC-6, IRC (70R/Class AA)(BL)
4) Moving (M.L)
5) Traction and braking (as per IRC-6) (BR)

6) Impact load(as per IRC-6) (IM)

7) Temperature gradient (as per IRC-6) (Temp)

8) Earth quake response spectra (EQRS)

9) Time history (Elcentro \& Coalinga)

Load combination:

1. Dead load of the superstructure(D.L.)

2. Dead Load + Prestress (D.L. + P.S)

3. Dead Load + Prestress + Moving Load (D.L.+ P.S. +M.L.)

4. Dead Load + Prestress + Moving Load + Temperature (D.L.+P.S.+M.L.+Temp.)

5. Dead Load + Prestress + Moving Load + Braking Load + Temperature (D.L.+P.S.+M.L.+B.R.+Temp.)

6. Dead Load + Prestress + Moving Load + Braking Load + Impact + Temperature (D.L.+P.S.+M.L.+B.R.+Temp.)

7. Dead Load + Prestress $+0.5 *$ Moving Load $+0.5 *$ Braking Load + Impact + Temperature(D.L.+P.S.+M.L.+B.R.+Temp.) 


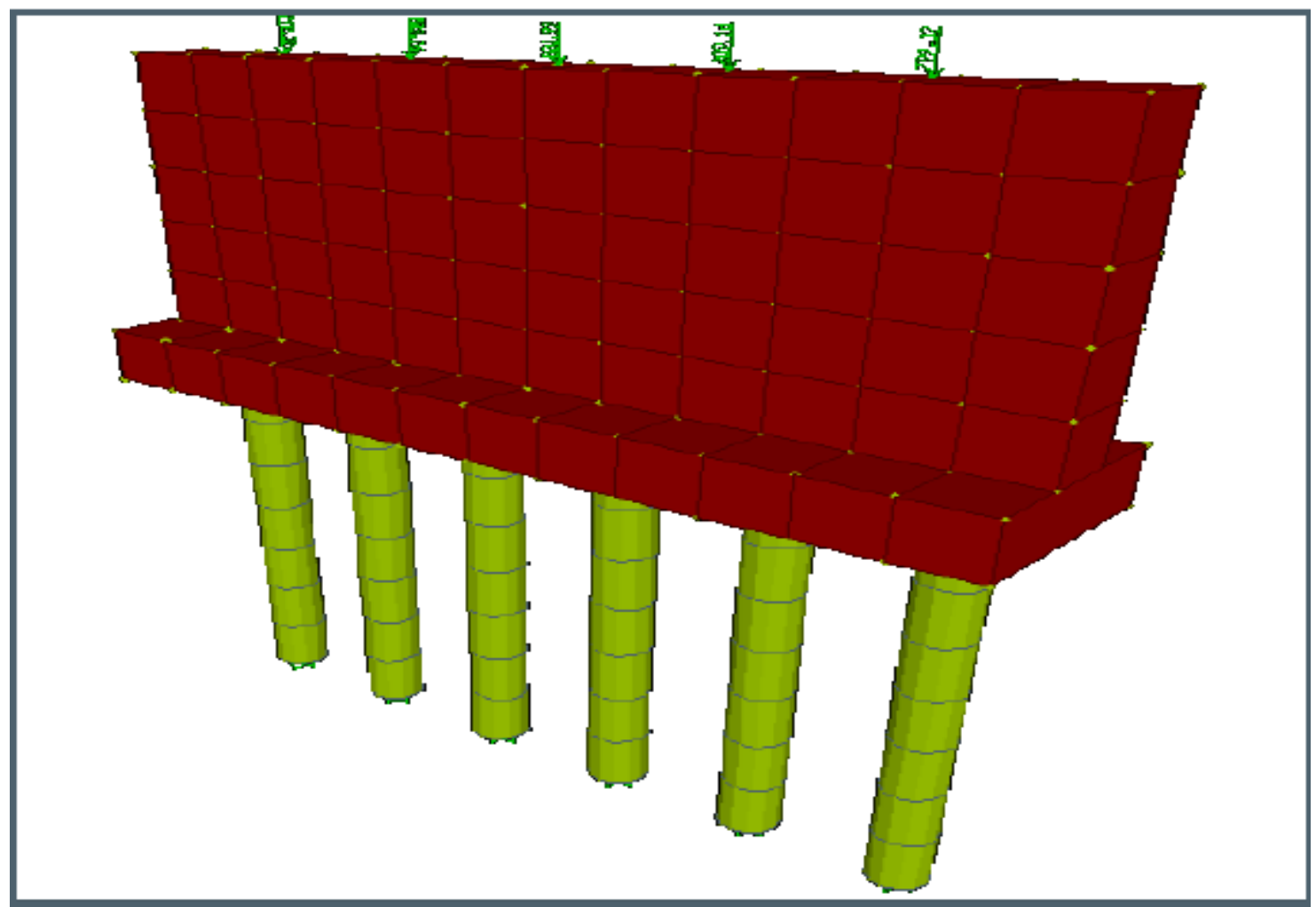

Fig.2 Typical abutment modelling in SAP2000

\section{RESULTS AND DISCUSSION}

The superstructure of the bridge is supported by bearings which rest on abutment $\&$ in turn rest on pile cap connected to piles. Normally we assume the foundation to be fixed but, the assumption is only valid in the case of structure that rest on a hard rock, whereas in case of soft soil the behaviour of soil and its interaction with the structure has to be determined. If the soil is very soft, when it is subjected to earthquake, it tends to loosen its bearing capacity and there will be chances of liquefaction which results in collapse of the structure. In the present study the soil is modeled as the springs whose stiffness are calculated based on the API (American Petroleum Institute) Guidelines. In practice all the supports of the bridges are not straight, the supports has to be constructed as skew to certain angles depending upon the field condition and necessity of the bridge. Hence a parametric study is carried out to study the behaviour of skewed abutment in comparision with the normal straight abutment. A finite element package SAP2000 V 14.2.4 is used for the analysis purpose and the results obtained from the normal abutment with and without soil structure interaction and that of the skew abutment with and without SSI are compared. These are subjected to the loads coming from the super structure and also subjected to the earth quake time history analysis of two earth quake:

(i) Elcentro earthquake

(ii) Coalinga earthquake

The time history data of the two earthquakes are scaled down to $0.15 \mathrm{~g}$ (since the peak ground acceleration for Bangalore region is $0.15 \mathrm{~g}$ ). The results obtained from time history analysis will be in terms of displacement, velocity and acceleration. 
Table 2 Summary of comparision of peak values of Displacement of Normal and skew abutment with and without SSI

\begin{tabular}{|c|c|c|c|c|c|c|c|c|c|}
\hline & \multicolumn{3}{|l|}{ With out ssi } & \multicolumn{3}{|l|}{ With ssi } & \multicolumn{2}{|c|}{$\begin{array}{ll}\text { Variation } & \text { of } \\
\text { frequency }\end{array}$} \\
\hline & & Displacement & Time & frequency & Displacement & time & frequency & increase & Decrease \\
\hline \multirow[t]{2}{*}{ ELCENTRO } & NORMAL & .095 & 5.1 & .196 & .002 & 3.56 & .281 & 1.43 & - \\
\hline & SKEW & .081 & 4.5 & .222 & .002 & 3.564 & .281 & 1.26 & - \\
\hline \multirow[t]{2}{*}{ COALINDA } & NORMAL & .11 & 21.9 & .046 & .001 & 7.854 & .127 & 2.79 & - \\
\hline & SKEW & .104 & 8.2 & .122 & .001 & 7.854 & .127 & 1.04 & - \\
\hline
\end{tabular}

Table 3 Summary of comparision of peak values of Acceleration of Normal and skew abutment with and without SSI

\begin{tabular}{|c|c|c|c|c|c|c|c|c|c|}
\hline & \multicolumn{3}{|l|}{ With out ssi } & \multicolumn{3}{|l|}{ With ssi } & \multicolumn{2}{|c|}{$\begin{array}{l}\text { Variation } \\
\text { frequency }\end{array}$} \\
\hline & & acceleration & Time & frequency & acceleration & Time & Frequency & increase & Decrease \\
\hline \multirow[t]{2}{*}{ ELCENTRO } & NORMAL & 1.301 & 2.1 & .476 & 3.439 & 5.016 & .199 & - & 2.39 \\
\hline & SKEW & 3.746 & 3.4 & .294 & 3320 & 5.016 & .199 & - & 1.48 \\
\hline \multirow[t]{2}{*}{ COALINDA } & NORMAL & 1.042 & 7.5 & .133 & 1.362 & 9.174 & .109 & - & 1.22 \\
\hline & SKEW & 4.723 & 8.1 & .123 & 1.315 & 9.174 & .109 & - & 1.13 \\
\hline
\end{tabular}

Table 4 Summary of comparision of peak values of Velocity of Normal and skew abutment with and without SSI

\begin{tabular}{|c|l|l|l|l|l|l|l|l|l|}
\hline \multicolumn{2}{|c|}{} & \multicolumn{2}{|l|}{ With out ssi } & \multicolumn{2}{l|}{ With ssi } & \multicolumn{2}{l|}{$\begin{array}{l}\text { Variation } \\
\text { frequency }\end{array}$} \\
\cline { 3 - 12 } \multicolumn{2}{|c|}{} & velocity & Time & frequency & velocity & Time & Frequency & increase & Decrease \\
\hline \multirow{2}{*}{ ELCENTRO } & NORMAL & .237 & 5.4 & .185 & .099 & 2.64 & .379 & 2.05 & \\
\cline { 2 - 11 } & SKEW & .505 & 4.7 & .213 & .096 & 2.64 & .379 & 1.78 & \\
\hline COALINDA & NORMAL & .20 & 21.3 & .047 & .027 & 9.108 & .110 & 2.34 & \\
\cline { 2 - 10 } & SKEW & .673 & 7.9 & .27 & .027 & 9.108 & .110 & & 1.15 \\
\hline
\end{tabular}

\subsection{Discussions}

1. From the of results it can be shown that the frequency of the abutment has increased with soil structure interaction model in comparision without SSI model for both cases of normal and skew abutment by, 1.43 and 1.26 times for Elcentro earthquake \& 2.79 and 1.04 times for Coalinga earthquake 2. It is observed that the acceleration response of all the four models have decreased for the models with SSI by, 2.39 and 1.48 times for Elcentro earthquake \& 1.22 and 1.13 for Coalinga earthquake Whereas the spectral acceleration of these models has increased by, 1.34 and 4.96 for Elcentro earthquake \& 4.96 and 4.96 for Coalinga earthquake

\section{CONCLUSIONS}

1. In the present study the behaviour of normal and skew abutment are studied with and without soil structure interaction.

2. It is observed that the reactions from the super structure to the abutment changes for normal and skew abutment for which all the loading conditions on the super structure kept constant.
3. The frequency of the normal abutment is $1.43 \mathrm{~Hz}$ whereas for skew it is $1.26 \mathrm{~Hz}$ which shows that the frequency reduces. 4. The displacements are compared for earthquake by equivalent static method, Response spectrum according to IS:1893-2002 (Part 1) for zone II, and earthquake time history of Elcentro and Coalinga in which the Peak Ground Acceleration (PGA) is scaled down to $0.15 \mathrm{~g}$. From all the above, the maximum displacement of $0.11 \mathrm{~m}$ was obtained in the case of Coalinga TH for Normal abutment without SSI.

5. The magnitude of acceleration of Normal abutment is amplified by 2.64 times and 1.307 times for Elcentro and Coalinga whereas it is reduced by 0.88 and 0.278 times respectively for skew abutment. Hence with the variation of skew angle there is variations in the performance of the abutment.

\section{REFERENCES}

[1] Shamsabadi, A., Rollins, K., and Kapuskar, M., (2006) "Nonlinear Seismic Soil- Abutment-Structure Interaction Analysis of Skewed Bridges", Journal of Geotechnical and Geo environmental Engineering, ASCE. 
[2] Anoosh Shamsabadi, Liping Yan and Geoffrey Martin., (2004) "Three Dimensional Nonlinear Seismic SoilFoundation-Structure Interaction Analysis of a Skewed Bridge Considering Near Field Effects", Journal of Geotechnical and Geo-environmental Engineering.

[3] S.Erhan \& M.Dicleli., (2010) "Effect of Dynamic SoilStructure Interaction Modelling Assumptions on Seismic Analysis of Integral Bridges",ECEE.

[4] N.P. Tongaonkar and R.S. Jangid (2003), "Seismic response of isolated bridges with soil-structureinteraction", Soil Dynamics and Earthquake Engineering, USA, Vol. 23, pp.287-302.

[5] Murat Dicleli, Suhail M. Albhaisi, "Performance Of Abutment Backfill System Under Thermal Variations In Integral Bridges Built On Clay" Engineering Structures, Vol 26, pp. 949-962, Feb 2004.

[6] Jianfeng Zhang, Ronald D. Andrus and C. Hsein Juang.,(2005) "Normalized Shear Modulus and Material Damping Ratio Relationships", Journal of Geotechnical and Geo environmental Engineering, ASCE, pp.453-464.

[7] Krishna Raju. N., "Design of Bridges (Fourth Edition)", Oxford and IBH Publishing Co. Pvt. Ltd., New Delhi.

[8] Eugenia Roman, Yasser Khodair and Sophia Hassiotis, "Design De-tails of Integral Bridges" Dept. of Civil Engineering And Ocean Engineering, Stevens Institute Of Technology, Hoboken N.J.

[9] Jolene L. Fennem, Jeffrey A. Laman, P.E. and Daniel G. Linzell, P.E.,(2005) "Predicted and Measured Response_ of an Integral Abutment Bridge", Journal of Geotechnical and Geo environmental Engineering, ASCE, pp.666-677.

[10] K. T. Brodbaek, M. Moller, S. P. H. Sorensen and A. H. Augustesen (2009) "Review of p-y relationships in cohesionless soil", Aalborg University, DCE Technical Report No.57.

[11] Veletsos, A.S. and Wei, Y.T. (1971): "Lateral and Rocking Vibration of Footings", J. Soil.Mech. Found. Div., ASCE, 97, 1227-1248. 